\title{
CORRECTION
}

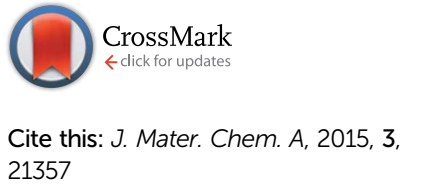

DOI: $10.1039 / \mathrm{c} 5 \operatorname{ta} 90218 \mathrm{e}$

www.rsc.org/MaterialsA

\section{Correction: Influence of the hydrophilic/ hydrophobic nature of polyetheramines on the interaction between amine-alcohol-silicate hybrids and anionic dyes for effective water cleaning}

\author{
André L. A. Moura, Lilian K. de Oliveira, Katia J. Ciuffi and Eduardo F. Molina*
}

Correction for 'Influence of the hydrophilic/hydrophobic nature of polyetheramines on the interaction between amine-alcohol-silicate hybrids and anionic dyes for effective water cleaning' by André $L$. A. Moura et al., J. Mater. Chem. A, 2015, 3, 16020-16032.

Reference 26 of the above manuscript is incorrect and should include the references as shown below.

26 (a) Y. S. Ho, D. A. J. Wase, C. F. Forster, Environ. Technol., 1996, 17, 71-77; (b) Y. S. Ho, Water Res., 2006, 40, 119-125; (c) J. A. Hefne, W. K. Mekhemer, N. M. Alandis, O. A. Aldaye and T. Aljvay, Int. J. Phys. Sci., 2008, 3, 281-288.

The Royal Society of Chemistry apologises for these errors and any consequent inconvenience to authors and readers. 